\title{
A Study on Vehicular Content Delivery
}

\author{
Subramanyam Kunisetti ${ }^{1}$ and Suban Ravichandran ${ }^{2}$ \\ ${ }^{1}$ Research Scholar, Department of Computer Science and Engineering, \\ ${ }^{2}$ Assistant Professor, Department of Information Technology, \\ ${ }^{1 \& 2}$ Annamalai University, Annamalai Nagar, Tamil Nadu, India \\ E-Mail: subramanyamkunisetti@gmail.com, rsuban82@gmail.com
}

\begin{abstract}
The presence of the net of Vehicles licenses comforts driving encounters and substance rich sight and sound framework administrations for in-vehicle clients. The movement arranges gives particular situation centrically content conveyance administrations including data of auto standing, client practices, and ecological choices. In this paper, we tend to target transport content conveyance from a gigantic in view of a data point. At the point when an exhaustive survey of dynamic works, we tend to expand the potential cost of huge data in vehicular information and substance benefits by presenting numerous regular application circumstances. Per the data qualities, we tend to group the transport data into 3 classes, that is, an area is driven, client-driven, and vehicledriven, and afterward represent relate execution of huge data arrangement and investigation. A true enormous data application in social-based transport systems is given, and reenactment results demonstrate that the tremendous data empowered substance conveyance technique will get an execution gain of client fulfillment with the conveyed substance compared to the case rudely of social huge information. At last, we tend to close the article with disjoining al future examination subjects.
\end{abstract}

Keywords: Vehicular Content, Vehicle-To-Vehicle, QoE, Big Data

\section{INTRODUCTION}

These days, the climb of versatile data activity has been fomenting changes of remote spec and improvements of remote advances. it's required that in respect to nowadays, a future fifth era (5G) portable correspondence framework can bolster a thousand times higher versatile data volume and 10 - 100 times the amount of associated gadgets. Vehicleconveyed data and in-vehicle gadgets have strived vital jobs since the help of value would be one key test for future remote data administrations and applications. Uncommonly, joined vital a piece of the future remote system, the net of Vehicles has risen to create cozy driving encounters and substance rich sight and sound framework benefits that can't be finished while not temperate data and substance conveyance. Thus, it's prominent that transport content conveyance has turned into a hot stock.

Recognized from a run of the mill correspondence organizes, the transport arrange includes particular situation driven substance conveyance. Vehicle areas, street conditions, and client practices would regularly affect the necessities and exhibitions of conveyance administrations. Suppose, once invehicle clients crash into an advertisement locale, they may wish to hoard information on stopping zone and eateries that meet their needs [1]. For another situation, drivers headed inside a similar bearing may have comparable data proportionate to the street and live activity reports, and option in-vehicle clients could ask for comparative mixed media framework substance. Every one of those assortments of substance might be conveyed by street side units (RSUs) downloading or vehicle-to-vehicle (V2V) [1] helped to send. It might be seen that transport content conveyance has quality in the region, time, and social relationship.

In spite of existing strong deals with substance conveyance in movement arranges, the transport data qualities haven't been completely researched, which may be the introduction of situation driven con-tent conveyance. To start with, area constructed content persistently depends in light of timefluctuating and connected math data that should be gathered and investigated to create viable driving information. Second, the social-mindful data that mirrors the inclinations of movement clients should be thought of to help the finish of substance sharing through $\mathrm{V} 2 \mathrm{~V}$ correspondences and extra enhance the system property and power. In addition, vehicle condition-based data might be connected to grow new applications and enhance the nature of skill (QoE). Particularly, the on highest points of thought of data have qualities of huge volume, variable sort, and time-shifting alteration, which may be raised as tremendous data. Thus, this rouses the USA to investigate transport con-tent conveyance from a goliath data point of view. However, the prospering realization of big-data-based conveyance content delivery isn't trivial. The foremost challenges area unit summarized as follows.

\section{A. Huge Scale Time Shifted Information}

The supply of transport learning changes from affixed spots to moving vehicles; the movement system could likewise be of gigantic scale taking after an engorged urban road; the vehicles may move at a fast, bringing about a very powerful system. Upheld the over reasons, transport learning territory unit expansive scale and time - fluctuating, which infers that it's relatively laborious to perform information examination.

Displaying Strategy upheld gigantic information Analysis: transport content conveyance administrations territory unit fundamentally excited by the learning requests of vehicles, which may be predicted by demonstrating the connections 
among vehicles and furthermore the earth and in additional areas, occurrences, and elective vehicles. The demonstrating methodology is frequently the best approach to search out a quantitative articulation of the connection to anticipate client conduct and inclination.

TABle I A Comprehensive Summary Of State-OF-The Art Progress

\begin{tabular}{|c|c|c|c|c|}
\hline Category & Literature & Feature & Merit & Limit \\
\hline \multirow{2}{*}{$\begin{array}{l}\text { Content-centric } \\
\text { networking or } \\
\text { information-centric } \\
\text { networking-based } \\
\text { vehicular content } \\
\text { delivery }\end{array}$} & .[4] & $\begin{array}{l}\text { Information-centric } \\
\text { networking }\end{array}$ & $\begin{array}{l}\text { Support vehicle mobility } \\
\text {.improve transmission rate }\end{array}$ & $\begin{array}{l}\text { Big data is ignored } \\
\text {.subtantial revisions } \\
\text { are required }\end{array}$ \\
\hline &.$[5]$ & $\begin{array}{l}\text { content-centric } \\
\text { networking } \\
\text {.D2D }\end{array}$ & $\begin{array}{l}\text {.content request offloading } \\
\text {.spectrum reuse }\end{array}$ & $\begin{array}{l}\text {.Big data is ignored } \\
\text {.Limited } \\
\text { performance } \\
\text { improvement }\end{array}$ \\
\hline \multirow{3}{*}{$\begin{array}{l}\text { Social-aware vehicular } \\
\text { content delivery }\end{array}$} &.$[2]$ & $\begin{array}{c}\text { Social characteristics } \\
\text { and behaviours }\end{array}$ & $\begin{array}{l}\text { A survey of the main features } \\
\text { of vehicular social networks }\end{array}$ & Big data is ignored \\
\hline & .[9] & Social swarms & Agent-base model & Big data is ignored \\
\hline & .[10] & $\begin{array}{c}. \mathrm{D} 2 \mathrm{D} \\
\text {.control and data } \\
\text { seperation }\end{array}$ & $\begin{array}{l}\text {.Group management } \\
\text {.Rpid data transfer }\end{array}$ & Big data is ignored \\
\hline \multirow{2}{*}{$\begin{array}{l}\text { Big-data based } \\
\text { vehicular netwworks }\end{array}$} & .[11] & $\begin{array}{c}. \mathrm{D} 2 \mathrm{D} \\
. \text { Exloring driving big } \\
\text { data }\end{array}$ & $\begin{array}{l}\text {.online an status aware } \\
\text {.unlabelked data }\end{array}$ & $\begin{array}{l}\text { Not related to } \\
\text { content delivery }\end{array}$ \\
\hline & .[12] & $\begin{array}{l}\text { Explore social big } \\
\text { data }\end{array}$ & $\begin{array}{c}\text {.overlapping and hierarchial } \\
\text { social clustering } \\
\text {.location prediction } \\
\end{array}$ & $\begin{array}{c}\text { Not related to } \\
\text { content delivery. }\end{array}$ \\
\hline
\end{tabular}

\section{B. Reconciliation with Communication Techniques}

The formed relationship should be incorporated with underlay correspondence systems to contrast the QoE for transport clients on substance conveyance. Along these lines, a joint multi-layer style should be taken into thought to accomplish an abnormal state smart office intelligent facility (ITS).

Likewise, it's imperative to make a major information empowered system for movement content conveyance. To achieve high QoE for movement clients, we tend to propose to blend colossal information innovation with current media get to administration layer and system layer advancements and additionally radio asset assignment, peer revelation of $\mathrm{V} 2 \mathrm{~V}$ joins, course enhancement, et cetera. Inside the accompanying areas, we tend to start gives a writing survey on movement content conveyance systems, thus expound the clarifications for utilizing immense learning great from the read of utilization. Next, we tend to order transport colossal learning into 3 classes, and furthermore legitimize the usage of information collection and examination. A contextual analysis identifying with certifiable enormous learning is presented to exhibit the pervasiveness of gigantic information empowered substance conveyance. At long last, we tend to finish up this content and depiction real examination open problems large-scale time differed information.

\section{LITERATURE REVIEW ON VEHICULAR CONTENT DELIVERY NETWORKS}

The substance conveyance issues in transport networks have drawn escalated consideration from every space and exchange. Table one gives an exhaustive framework of the condition of the - workmanship commitments in transport content conveyance and thusly the reconciliation of enormous data with movement systems.

There is a unit a few works that location the vehicular substance conveyance downside from a substance-driven or data-driven point of view. In [5], Amadeo et al., anticipated partner data-driven systems administration essentially based substance conveyance structure to manage the difficulties caused by low-quality remote connections and high caliber of vehicles. Su et al., researched the practicability of vehicle-to-foundation (V2I) data offloading by investigating gadget to-gadget (D2D) joins among set vehicles, contentdriven systems administration hubs, and moving vehicles. With the correct style of enthusiasm causing, content dispersion, and substance substitution, the substance demands sent to frameworks might be viably offloaded by substance driven systems administration hubs conveyed in social spots.

An alternate profession keeps an eye on the development of content movement issues by researching transport social affiliations in light of social characteristics and human practices bigly influence the decentralized timeserving trades among vehicles. A diagram of the best in class on transport casual networks was given in, and along these lines, the options of development relational associations including progressions, applications, examination issues, and potential courses of action were addressed by and by foreseen a social vehicle swarm-based vehicular correspondence approach by combining the likelihood of natural swarms with social-careful transport content scattering. In, a D2D-based period social-enabled transport spec was foreseen for substance scattering. Decoupling of 
the organization and information planes was utilized to energize moderate social occasion organization and speedy information trade. With mammoth volumes of data gathered in every aspect of transport systems, enormous information based vehicular correspondence methods that may gain from the verifiable data and adjust commonplace asset allotment style to information-driven applications turned out to be ever indispensable.

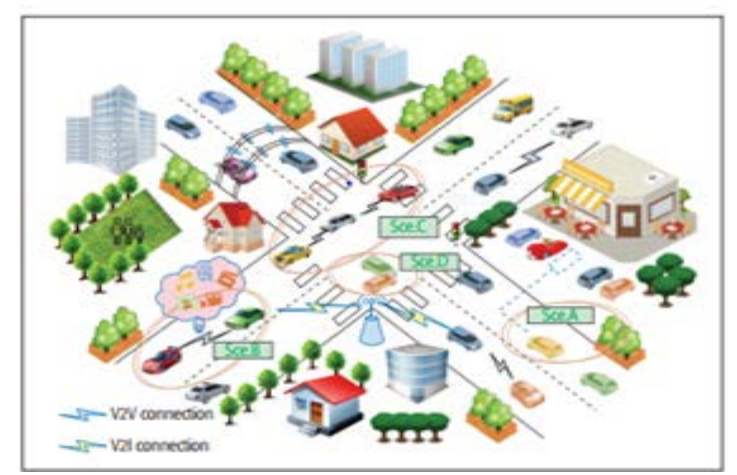

Fig. 1Vehicular networks withfour typical applications Scenarios of big data

An on the web and status-mindful driving irregularity distinguishing proof methodology was anticipated in [12]. The on-line data stream is part into sections, that region unit at that point contrasted with the built-up conduct model to spot driving oddity. In [13], Lin et al., researched totally extraordinary degrees of logical hypothesis among vehicles and anticipated a transport confinement lead by investigating social huge information based over-lapping and hierarchic social cluster models.

In outline, the on highest points of made reference to works have practical experience in either limited parts of transport content conveyance or huge information based movement applications love driving abnormality recognition and restriction. There's inadequate with regards to a bound together system for an approach to use genuine enormous data to improve content conveyance execution underneath various application circumstances.

\section{A. Why Use Big Data}

A standard model of a vehicular network. It's step by step been recognized that massive information will offer advantages in sanctionative vehicle applications and up transportation watching. Next, we offer four typical application eventualities to elaborate the worth of huge information approaches to transport content delivery.

\section{B. Administration Information Delivery}

As a run of the mill utilization of transport data, benefits information much the same as climate reports, stopping regions, movement conditions, driving courses and areas of eateries will encourage drivers to relish higher driving encounters. In particular, benefit providers will convey right and powerful information upheld various gathered period data. suppose, by gathering data on client tastes, wellbeing conditions, menus, and open acclaim of close eateries, transport delicate product offers proposal on an eating place, and furthermore the associated information similar to stopping regions and assortment of people looking for administration is conveyed to the vehicle (as appeared in situation An in Fig.1). The total execution is predicated on grouping and investigation of individual client data and natural data.

A key work of V2V transmission is to share picture indicate substance, suppose, music, recordings, maps, and elective mixed media framework documents, among vehicles, which may encourage to dump data from huge load foundations and scale back transmission defer on account of the nearness interface.

In particular, vehicular clients with comparative interests may ask for comparative substance. Possibly, clients heading toward indistinguishable goal some of the time need indistinguishable driving course; comparable age travelers may ask for indistinguishable hot video. In such cases, vehicle activity data, street information, and client conduct data should be consolidated and dissected to foresee clients' inclinations, and more offer a social relationship.

Model to reflect the substance decision similitude's of transport clients. Along these lines, the asked for infotainment substance will be shared or pushed among vehicles with vigorous social ties, accomplishing socialbased substance conveyance.

\section{Cooperative Content Delivery}

Helpful transfer transmission could be promising systems that may grow organize inclusion and certification arrange property. On account of rapidly moving vehicles, there's an incredible plausibility that the channel condition between 2 vehicles or among vehicle and foundation can't bolster an immediately single-bounce interface. In this manner, V2V agreeable hand-off has normally turned into a huge application that helps 2 vehicles (as appeared in situation C in Fig. 1) or a V2I interface with an interior direct channel to convey. very surprising from standard hand-off transmissions, on one angle, vehicle-helped handing-off should introductorily guarantee that the vehicle gadget as transfer holds save electrical vitality that may fulfill the standard of administration (QoS) all through the substance sending technique.

On the contrary perspective, the speedy nature of vehicles winds up in a dynamic arrangement inside which even the unreliability of short-separate supporter stations can't be totally justified. Subsequently, it's natural to investigate a gigantic - information-based way to deal with assessing the capacity utilization, the affiliation probability, and elective markers for building up sponsor stations. Vehicle-based 
data, together with the electric sum, speed, driving bearing, et cetera, should be examined to enhance transfer as-sited content conveyance.

\section{Data Delivery with Safety}

Safe driving is one among the essential issues that ITS underlines. Vehicle learning that presents vehicle state information, together with fuel amount, electrical sum, and furthermore the wear state of tires, alongside driving learning together with speed, exceptionally tension, and separation between vehicles, should be gathered and broke down to pass judgment on the sheltered condition of vehicles; at that point the framework will convey alert information thus. Moreover, mishap feeling conveyance depends on every semi-perpetual recognition of ecological learning and complete arrangement of auto-state information. Per a report by the U.S. Bureau of Transportation. Lice-reported crashes a year. State of affairs $\mathrm{D}$ in Fig. one is associate degree example of accident premonition delivery, wherever premonition data may be delivered to vehicles that are terribly possible to drive through a junction by analyzing the information in previous accident reports.

TABLE II Classification Of VeHicular Big DATA

\begin{tabular}{|c|c|c|c|c|}
\hline Category & source & Data & Feature & Usage scenario \\
\hline Location-centric & $\begin{array}{l}\text { RSUs } \\
\text { BS } \\
\text { Handheld devices } \\
\end{array}$ & $\begin{array}{l}\text { Traffic conditions } \\
\text { Traffic accidents } \\
\text { Environmental conditions }\end{array}$ & $\begin{array}{l}\text { Diverse } \\
\text { Periodical } \\
\text { Event-triggered } \\
\end{array}$ & $\begin{array}{l}\text { Service information delivery } \\
\text { Safety information delivery }\end{array}$ \\
\hline User-centric & $\begin{array}{l}\text { Online social platforms } \\
\text { Physical networks }\end{array}$ & $\begin{array}{l}\text { Gender } \\
\text { Age } \\
\text { Education } \\
\text { Historical Access }\end{array}$ & $\begin{array}{l}\text { Large Volume } \\
\text { Multidimensionality } \\
\text { Long-term capture } \\
\text { Easily being affected }\end{array}$ & $\begin{array}{l}\text { Social-welfare content delivery } \\
\text { Service information delivery }\end{array}$ \\
\hline Vehicle-centric & $\begin{array}{l}\text { Vehicle sensors } \\
\text { Driving recorders }\end{array}$ & $\begin{array}{l}\text { Quality of fuel } \\
\text { Quality of electricity } \\
\text { Speed } \\
\text { Acceleration } \\
\text { Deceleration } \\
\text { Distance traveled } \\
\text { braking }\end{array}$ & $\begin{array}{l}\text { Periodical } \\
\text { Long-term capture } \\
\text { Reflecting driving habits }\end{array}$ & $\begin{array}{l}\text { Cooperative content delivery } \\
\text { Safety information delivery }\end{array}$ \\
\hline
\end{tabular}

\section{PROPOSED METHOD}

\section{A. Grouping and Implementation}

As per the higher than elaboration, transport tremendous information might be a need that not exclusively animates new administrations and applications, anyway also upgrades transport arrange execution and consequently the driving mastery. Next, we tend to give a grouping of transport tremendous learning, and after that give the execution of information variety and investigation. Safe driving is one among the essential issues that ITS puts weight on. Vehicle discovering that presents vehicle state data together with fuel aggregate, electric entirety, wear condition of the tire, nearby driving data together with speed, change pressure, expel between vehicles, ought to be assembled and analyzed to evaluate the secured state of vehicles, by then the structure will pass on.

\section{B. Grouping of Vehicular Big Data}

1. Classification of Conveyance Massive Information: Based on the info sources and assortment methods, we tend to divide conveyance massive information into 3 categories, as summarized in Table two.

2. Location-Centric Massive Data: This sort of data is essentially gotten from a decent style of geographical areas [2]. To Illustrate, in an exceedingly full urban road, data of movement conditions are generated from recognition the amount/period of time/period\} assortment of vehicles ignoring through an intersection a concise timeframe; data of car crashes are gathered from a perilous segment of mountain streets over numerous months. The area driven gigantic data constantly includes various data sorts comprising of tremendous amounts of vehicles, clients, and natural conditions, and may be acquired by either periodical recognition or occasion activated exercises. In movement organizes, the information is regularly gathered by means of RSUs, the base station (BS), or hand-held gadgets furnished with application stages news to the foundation servers. Clearly, this sort of \{information\} would be primarily connected in commission information conveyance and security data conveyance.

3. User-Centric Massive Data: A social-mindful content conveyance system relies upon social connections among movement clients that should be modeled steady with the similitudes of client interests. In particular, interests are reflected by client properties taking after sex, age, training background, and chronicled data of client get to. Therefore, amid this case, transport content conveyance depends on client-driven gigantic data that have choices of colossal volume, multidimensionality, semi changeless catch, basically being experiencing outer elements, et cetera. In the interim, this sort of \{information\} may likewise be connected to benefit data conveyance; to Illustrate, eating place proposal is finished upheld data of client inclinations. 
Each the social relationship and client inclinations are described by on-line informal organizations created inside the web stages, and also by physical systems created by vehicle experiences and situations.

4. Vehicle-Centric Massive Data [1]: As already made reference to, vehicle state information prevent mines regardless of whether the vehicle will go about as a handoff to help V2V or V2I joins convey substance, and also reflects the security remaining of vehicles and any helps the framework to deliver crisis caution or mishap hunch. Vehicle-based generally or driving data are regularly no inheritable by vehicle sensors and driving recorders, that gather information with respect to the rest of the amounts of fuel and power, speed, increasing speed, speed, separate voyaged, braking hones, et cetera. The vehicular gadget gathers driving data over a measure of days to months and sporadically transfers the information to a foundation server. The data reflecting driving propensities are vehicledriven, and will be joined with client driven data to perform further examinations of transport client practices. \{We can/we will/we are capable to $\}$ reason that this sort of data is predominantly connected in helpful conveyance and wellbeing data conveyance inevitabilities.

\section{Implementation of Huge Information Assortment and Analysis}

In the underlying spot, the framework needs to gather the transferred data from transport gadgets, disseminated arrange hubs, and slither client related data from movement programming framework stages. At that point, the highlights of gathered data that speak to vehicle states, information on open offices, and movement client intrigues should be separated. From that point onward, the framework performs data preprocessing to improve the standard of data. A learning purging activity is required to determine irregularities and take away commotion. Along these lines, imperative choices of vehicles, offices, and clients are removed and continue making a dataset.

Existing information analytical tools for wireless communication areas embrace random modeling, data processing, machine learning, and alternative large-scale information analytics. For the movement content conveyance drawback, it wants a far-reaching use of those apparatuses.

To Illustrate, the quality expectation is regularly made by coordinating this trip of a vehicle to its quality profile, that has a place with the extent of data mining. For one more, the extraction of transport client interests needs to build up a deliberate connection between past visited data and future activities, thus any foresee the decision likenesses of infotainments for movement clients and accomplish social connection foundation. Some data examination ways are recorded.

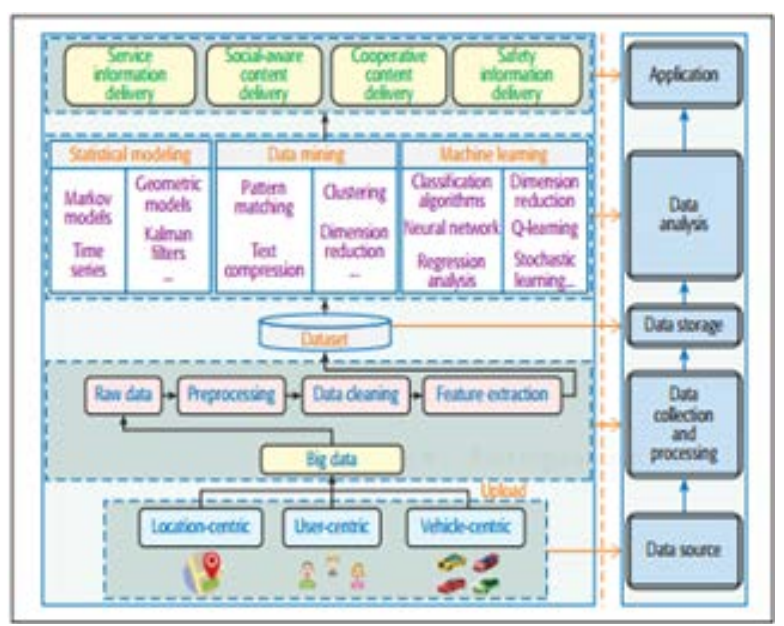

Fig. 2 Implementation of vehicular data collection and analysis

\section{A Case Study of Big-Data-Enabled Vehicular Content Delivery}

In this area, we tend to bless a contextual investigation of social gigantic learning based for the most part content conveyance in D2D-based movement systems, and furthermore the technique for data variety, preparing, and examination has appeared in Fig.3. There square measure K cell client gear, $\mathrm{M}$ potential D2D-V transmitters (content suppliers), and M D2D-V collectors (content requesters).

Each CUE is designated with Asymmetrical asset square, which might be reused by at the most one D2D-V join. We tend to research the aggregate rate improvement for $\mathrm{D} 2 \mathrm{D}-\mathrm{V}$ matches that includes the best approach to coordinate D2D $\mathrm{V}$ transmitters and collectors, the best approach to divide the transmission control, and the best approach to pick the asset to obstruct for each D2D-V join.

We will blend each the physical and social layer information for up the substance conveyance execution. a great deal of particular, a D2D-V transmitter and collector consolidate should meet beyond any doubt predefined physical and social layer necessities to make a D2D-V connect. Inside the physical layer, the D2D-V combine creation relies upon the association chance between the $\mathrm{D} 2 \mathrm{D}-\mathrm{V}$ transmitter and beneficiary that mirrors the dynamic untrustworthiness of transport associations identifying with high caliber. Inside the social layer, the establishment of D2D-V affiliation relies upon the social relationship force, that will be that the opportunity to pick comparative substance. Inside the accompanying, we tend to at first present the best approach to gauge the physical and social layer data as far as affiliation possibility and social relationship force, with AN accentuation while in transit to pass judgment on the substance inclinations bolstered genuine social gigantic information. By consolidating each the physical and social layer information, we tend to plan the transport content conveyance downside as a joint associate disclosure, channel decision, and power administration streamlining disadvantage, and propose a 
valuing based 3 - dimensional coordinating answer. Coordinating hypothesis is a conservative instrument for depicting the arrangement of reliant connections and has been broadly used in system asset distribution. In conclusion, recreations are directed to show the adequacy and predominance of social enormous trial movement content conveyance by investigating social learning gathered from the most critical Chinese micro blogging administration, Sina Weibo, and furthermore the biggest Chinese video sharing site.

\section{E. Content Delivery Strategy}

In the physical layer, outline the association time in terms of the mean initial passage time as $\mathrm{T}$ that may be a stochastic variable and depends on the initial headway distance and rate variations between the 2 vehicles. The headway distance may be represented as a Wiener method, and also the time evolution of the chance density perform (PDF) of auto rate within the Wiener method may be shapely by the Kolmogorov equation. Hence, the association chance in terms of the accumulative distribution performs (CDF) of the connection time T, that is, Pr may be derived supported the PDF of the headway distance. A lot of details may be found.

In the social layer, the social relationship intensity in terms of content choice similarity is estimated supported social massive knowledge collected from SinaWeibo and Youku. We've got designed an online crawler to extract billions of tweets from thousands of SinaWeibo active users at intervals a biennial time span. Since an oversized range of SinaWeibo users conjointly share video clips they notice attentiongrabbing on micro blogs via short URLs linking to a video entry on Youku, we will follow these URLs and extract options of every video as well as title, category, read range, then on from the individual profile page through Youku's application programming interface.

At that point, we tend to perform learning preprocessing to improve the standard of the gathered information. Learning enhancement is connected to determine irregularity and take away clamor. Possibly, we tend to enlarge video labels from Youku with semantics data to dodge disarray caused by label uncertainty and heterogeneity. A short time later, crucial choices of con-tent inclination square measure gathered to make a dataset. To thoroughly investigate the potential cost of social huge information, we tend to gather the choices from a scope of points of view like statistic trait, content characteristic, organize quality, and transient property.

Regular steady learning systems don't appear to be fitting to deal with social gigantic information with the monster spatial property. Subsequently, we tend to utilize a nonparametric learning approach named Bayesian measurement learning (BNL), which may abstain from over fitting or under fitting by putting a past circulation on the unending dimensional parameter house. One favorable position given by $\mathrm{BNL}$ is that the precision of estimation might be mechanically enhanced in light of the fact that the extent of found learning ends up bigger. By demonstrating the past information of likelihood conveyance as a Dirichlet strategy, the PDF of the possibility appropriation of equivalent substance selection might be acquired bolstered the recorded perception sets. The expound numerical induction might be found in [6], and is precluded here as a result of the house constraint. Define the thresholds of association chance and social relationship intensity as $h$ and $\mathrm{d}$, respectively. For any D2D-V transmitter I and receiver $\mathrm{j}$, a D2D-V combine is allowed if and given that each the corresponding association chance hi,j and also the social relationship intensity $\mathrm{di}, \mathrm{j}$ area unit higher than the thresholds, that is, hi,j $\geq \mathrm{h}$, and di, $\geq \mathrm{d}$.

To portray the effects of alliance prob-capacity and social relationship force on the transmission rate, the objective work is plot on the grounds that the transmission rate weighted by the physical-social score. The weighted transmission rate is expanded by finding a joint associate disclosure, control administration, and channel decision drawback, that is genuinely a three-dimensional coordinating among D2D-V transmitter, beneficiaries, and asset squares. The improvement factors territory unit the consistent transmission control, and furthermore the arrangement of companion disclosure and channel decision techniques that zone unit signified as a three-dimensional $\mathrm{M}$ $\times \mathrm{M} \times \mathrm{K}$ grid $\mathrm{O}=$ with paired segments. $\mathrm{Oi}, \mathrm{j}, \mathrm{k}=$ one speaks to that D2D-V transmitter I and collector $\mathrm{j}$ compose a D2D$\mathrm{V}$ attempt bolstered nuclear number $37 \mathrm{k}$. The QoS needs of each D2D-V connect and cell interface are pondered as limitation conditions.

The created joint associate revelation, control administration, and channel decision drawback are settled amid a tractable way by the anticipated pricing-based threedimensional coordinating recipe. In the first place, by joining D2D-V recipients and asset squares to make a substitution asset mix, we have a tendency to modify the initial three-dimensional coordinating into a 2 - dimensional coordinating, that includes M D2D-V transmitters on one angle and $\mathrm{M} \times \mathrm{K}$ asset combos on the contrary perspective. inside the 2 - dimensional coordinating, M D2D - V transmitters and MK asset combos zone unit coordinated with each other upheld the inclination records, that region unit formed from the perspectives of the most feasible weighted transmission rates. At that point, the twodimensional coordinating is upheld bolstered the great GaleShapley coordinating algorithm. when various D2D-V transmitters are coordinated with an identical asset mix, an estimating based subject is utilized to determine the contention. each asset mix is doled out with a virtual incentive to reflect the coordinating worth, the underlying cost of which may be set as zero. when numerous transmitters propose to be coordinated with a proportional asset blend, the relate ing virtual esteem is gathered by a stage of e. The coordinating technique is intermittent yet again upheld the new refreshed virtual esteem, that is constantly collected until just 1 transmitter remains. 


\section{SIMULATION AND RESULTS}

In this portion, the execution of the ace presented algorithmic program is assessed bolstered the information acquired from SinaWeibo and Youku. The cell span is five hundred $\mathrm{m}$. The length and broadness of the street stage zone unit one hundred $\mathrm{m}$ and ten $\mathrm{m}$, severally. The space between the base station and in this way the street stage is one hundred $\mathrm{m}$. the most transmission separate took into consideration $\mathrm{D} 2 \mathrm{D}-\mathrm{V}$ interface establishment is one hundred $\mathrm{m}$. the most transmission intensity of D2D-V transmitter is five hundred $\mathrm{mW}$, while cell transmission control is two hundred $\mathrm{mW}$. The trail misfortune types of cell join, D2D-V joins, CUE to D2D-V recipient connections and D2D-V transmitter to BS joins region unit three, 3.5, 4, and 3, severally. The QoS requirements zone unit indicated as zero. $5 \mathrm{~b} / \mathrm{s} / \mathrm{Hz}$.

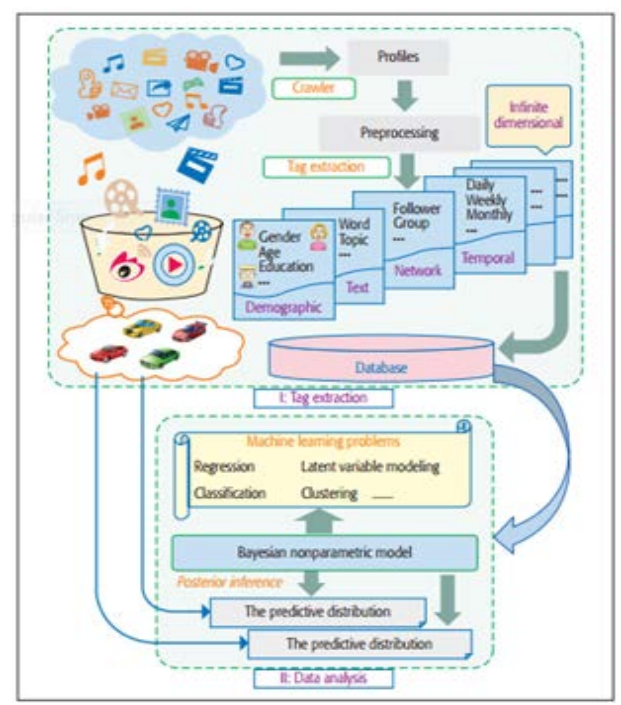

Fig. 3 Big-data based relationship prediction in vehicular networks

\section{CONCLUSION AND OPEN ISSUES}

Conclusions and Open issues in this article, we've point by point the vehicle content conveyance drawback from a tremendous data viewpoint. As a hot load of transport systems, information and substance administrations are regularly with productivity achieved by utilizing gigantic data obtaining and examination. We've inspected the dynamic takes a shot at associated points, so accentuated the need of applying huge data innovation to transport content conveyance. We've arranged the vehicle data into 3 classes, that is, area - driven, client-driven, and vehicle-driven, relate degreed also delineated a usage of gigantic data variety and investigation. A genuine huge data application in socialbased transport systems has been given to show the potential worth of huge data approaches in transport content conveyance. To understand a ton of adaptable, viable, and more secure structure for substantial information empowered transport content conveyance, numerous examination subjects got the chance to be additionally explored.
Big Data-Enabled Caching in transport Content Delivery: Distributed caching could be a considerable answer for coping with heavy-load infrastructures and severe network latency. In transport networks, a vehicle will cache the content that its neighboring vehicles in all probability want promptly, and deliver the content simply once they request. Currently, there's a shortage of sensible caching and resource allocation methods. Big-data-enabled caching that involves transport user behaviors and vehicle standing will give a promising direction for quick content delivery.

Distributed massive information Analysis in transport Content Delivery: totally different from general user information, transport information very quickly, therefore it's very difficult to conduct massive information analysis to satisfy the tough delay needs. Hence, distributed information analysis approaches resembling edge computing area unit essential for big-data-based transport content delivery. For future systems, in-vehicle devices or RSUs distributed at the sting of transport networks will share their computing resources to assist networks to have the capability for quick information processing and analysis.

The freshness of transport Data: on account of the highlights of fast vehicles, brisk lessening channels, and progressively regularly evolving setup, transport data unendingly wind up outdated in the blink of an eye, which infers that data freshness ought to be considered as a key issue. Period and temperate data arrangement and process methodologies should be embraced to ensure that the data of clients, vehicles, and conditions region unit apace got and transport content conveyance is successfully performed.

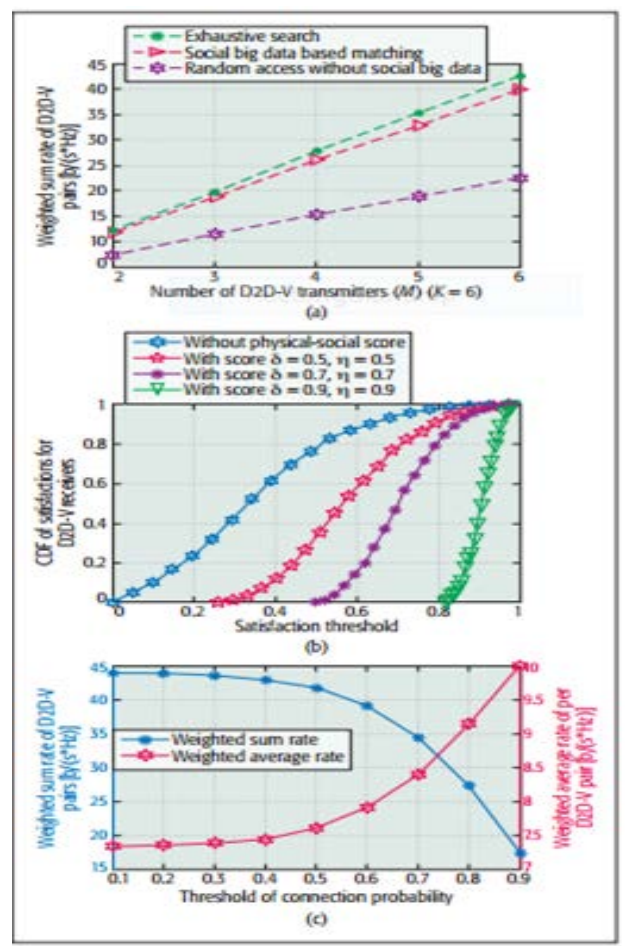

Fig. 4 a) Performance comparison among different algorithms on weighted sum rate of D2D-V pairs b) Satisfaction of vehicle users 


\section{SECURITY AND PRIVACY OF TRANSPORT DATA}

Security and protection issues have normally risen inside the period of huge data. Transport data talks about with data of not exclusively clients anyway moreover vehicles, and subsequently should be provided with higher security and protection. Suppose, in accordance with the choices of transport data, the system administrators will set up a classcognizant data coding framework to maintain a strategic distance from access and change by unapproved elements. Secure and efficient preparing and capacity procedures should be created to keep up the classification of client and vehicle data.

\section{REFERENCES}

[1] Chen Xu, Zhenyu Zhou, "Vehicular Content Delivery: A Big Data Perspective”, IEEE Wireless Communications, 2018.

[2] P. Popovski et al., "Scenarios, Requirements and KPIs for 5G Mobile and Wireless System”,ICT-317669-METIS/D1.1, Apr. 2013.

[3] A. Vegni et al., "A Survey on Vehicular Social Networks", IEEE Commun. Surveys and Tutorials, Vol. 17, No. 4, pp. 2397-2419, July 2015.

[4] R. Yu et al., "Cooperative Resource Management in Cloud-Enabled Vehicular Networks”, IEEE Trans. Ind. Electron., Vol. 62, No. 12, pp. 7938-51, Dec. 2015.
[5] M. Amadeo et al., "Information-Centric Networking for Connected Vehicles: A Survey and Future Perspectives", IEEE Commun. Mag., Vol. 54, No. 2, pp. 98-104, Feb. 2016.

[6] Z. Su et al., "D2D-Based Content Delivery with Parked Vehicles in Vehicular Social Networks”, IEEE Wireless Commun., Vol. 23, No. 4, pp. 90-95, Aug. 2016.

[7] C. Xu et al., "Social Network-Based Content Delivery in Device-toDevice Underlay Cellular Networks Using Matching Theory”, IEEE Access, Vol. 5, pp. 924-37, Nov. 2016.

[8] K. Wang et al., "Wireless Big Data Computing in Smart Grid", IEEE Wireless Communication, Vol. 24, No. 2,58-64, Apr. 2017.

[9] Y. Zhang et al., "Social Vehicle Swarms: A Novel Perspective on Socially Aware Vehicular Communication Architecture”, IEEE Wireless Communion, Vol. 23, No. 4,82-89, Aug. 2016.

[10] H. Li et al., "VeShare: A D2D Infrastructure for Real-Time SocialEnabled Vehicle Networks", IEEE Wireless Commun, Vol. 23, No. 4, pp. 96-102, Aug. 2016.

[11] M. Zhang et al., "SafeDrive: Online Driving Anomaly Detection from Large-Scale Vehicle Data”, IEEE Trans. Ind.Informat., Vol. 13, No. 4, pp. 2087-96.

[12] K. Lin et al., "Localization Based on Social Big Data Analysis in the Vehicular Networks”, IEEE Trans. Ind. Information, Vol. 13, No. 4 pp. 1932-40.

[13] M. Burt et al., "Big Data's Implications for Transportation Operations: An Exploration”, [Online] Available at: http://www.its.dot. gov/index.html,Dec. 2014

[14] S. Bi et al., "Wireless Communications in the Era of Big Data", IEEE Commun. Mag., Vol. 53, No. 10, pp. 190-99, Oct. 2015.

[15] T. H. Luan et al., "Feel Bored? Join Verse! Engineering Vehicular Proximity Social Networks", IEEE Trans. Vehic. Tech., Vol. 64, No. 3, pp. 1120-31, Mar. 2015 